\title{
The role of sonic hedgehog signaling pathway in in vitro oocyte maturation
}

\author{
Sanghoon Lee and Jongki Cho* \\ Laboratory of Theriogenology, College of Veterinary Medicine, Chungnam National University, Daejeon 34134, Korea
}

Received November 18, 2021

Revised November 25, 2021

Accepted November 25, 2021

\section{*Correspondence}

Jongki Cho

E-mail: cjki@cnu.ac.kr

Author's Position and Orcid no.

Lee S, Assistant professor,

https://orcid.org/0000-0002-1265-3821

Cho J, Professor,

https://orcid.org/0000-0002-8431-0457

\begin{abstract}
In vitro maturation (IVM) of oocytes is the procedure where the immature oocytes are cultivated in a laboratory until they are mature. Since IVM oocytes generally have low developmental competence as compared to those matured in vivo, development of an optimal IVM culture system by fine-tuning culture conditions is crucial to maintain high quality. In-depth knowledge and a deep understanding of the in vivo physiology of oocyte maturation are pre-requisites to accomplish this. Within ovarian follicles, various signaling pathways that drive oocyte development and maturation regulate interaction between oocytes and surrounding somatic cells. This review discusses the sonic hedgehog $(\mathrm{SHH})$ signaling pathway, which has been demonstrated to be intimately involved in folliculogenesis and oocyte maturation. Advances in elucidating the role of the $\mathrm{SHH}$ signaling pathway in oocyte maturation will aid attempts to improve the current inferior in vitro oocyte maturation system.
\end{abstract}

Keywords: in vitro oocyte maturation, ovarian follicle, sonic hedgehog signaling

\section{INTRODUCTION}

Oocyte maturation is a physiological process that precedes and is essential for successful fertilization and subsequent embryonic development (Lonergan and Fair, 2016). This process is initiated a few days prior to ovulation and involves progressive changes in ovarian follicles. These include preantral to early antral transition (Palma et al., 2012) and eventual acquisition of competence to resume meiosis and fertilizability (Paulini et al., 2014). Oocyte maturation is characterized by both nuclear and cytoplasmic maturation. The former is a complicated process that includes the resumption of meiosis post luteinizing hormone (LH) surge or oocyte release from a follicle (Luciano and Sirard, 2018). Mammalian oocytes enter the early stages of meiosis during fetal life but remain arrested at prophase I until they become committed to ovulation in response to an LH surge (Grøndahl, 2008). Meiotic resumption induced by the LH surge is further stalled at metaphase II (Lonergan and Fair, 2016) which is then completed following fertilization (Grøndahl, 2008). In contrast, cytoplasmic maturation is associated with organelle reorganization and storage of mRNAs, proteins, and transcription factors that are requisites for early embryonic development (Ferreira et al., 2009).

In vitro maturation (IVM) of oocytes refers to controlled maturation of retrieved immature oocytes under specific culture conditions in vitro (Hatırnaz et al., 2018). However, retrieval of immature oocytes followed by IVM perturbs oocyte maturation and subsequently results in a reduction of oocyte quality. One of the contributing reasons is believed to be improper IVM culture conditions primarily due to inadequate culture medium composition. Consequently, while nuclear maturation of IVM 
oocytes can be completed, cytoplasmic maturation usually remains incomplete, thereby possibly leading to poor embryonic development (Marchal et al., 2003). Since the nuclear maturation of oocytes must be accompanied by a variety of events that occur within the cytoplasm to complete embryonic development (Krisher, 2004), various attempts have been made to improve developmental competence of IVM oocytes in different species, including pigs (Appeltant et al., 2016; Jeon et al., 2020), cattle (Abd El-Aziz et al., 2016), and camels (Moawad et al., 2020; Saadeldin and Cho, 2021). These include supplementation of porcine IVM medium with antioxidants such as resveratrol (Lee et al., 2015) and spermine (Jin et al., 2016) to scavenge reactive oxygen species produced during the IVM process. In addition, attempts to mimic the intrafollicular environment have involved the addition of precursors of cholesterol synthesis, such as lanosterol (Lee et al., 2016) and follicular fluid meiosis-activating sterol (FF-MAS) (Marín Bivens et al., 2004) to porcine or mouse IVM medium. Furthermore, pre-IVM incubation with dibutyryl cAMP (dbcAMP; the cAMP analog) and 3-isobutyl1-methylxanthine (IBMX, a phosphodiesterase inhibitor) improved bovine IVM by elevating cAMP levels (Sugimura et al., 2018). However, despite these efforts, IVM oocytes continue to possess lower developmental competence as compared to those matured in vivo. Elucidation of the mechanisms involved in oocyte developmental competence is therefore essential to develop strategies for further improvement of IVM efficacy. This in turn requires a better understanding of the in vivo physiology of oocyte maturation in order to be able to optimize IVM culture conditions for better performance.

The functional unit of the ovary i.e. the ovarian follicle, consists of three types of cells: an oocyte, granulosa cells, and theca cells that provide an appropriate developmental environment for oocytes (Gougeon, 1996). Growing ovarian follicles demonstrate a bidirectional communication between the oocyte and surrounding somatic cells that is essential for appropriate proliferation and differentiation (Nilsson and Skinner, 2001). These communications are regulated by several classical signaling pathways, including the Wnt, insulin, Notch, and hedgehog (HH) pathways (Li et al., 2021). Wnt signaling pathway activation by Wnt2 and Wnt4 plays a crucial role in normal ovarian follicle development by promoting granulosa cell proliferation (Boyer et al., 2010; Wang et al., 2010). The insulin signaling pathway regulates follicle development in the later stages of oocyte growth and promotes oocyte development by either upregulating the binding efficacy of LH to receptors or the number of receptors itself (Das and Arur, 2017). The Notch signaling pathway is known to regulate granulosa cell proliferation, since treatment with a Notch signaling inhibitor resulted in a significant decreased in their number (Jing et al., 2017). Lastly, the HH signaling pathway has been postulated to be a target signaling pathway in ovarian follicle development, since expression of $\mathrm{HH}$ ligands at the primary follicle stage is well established (Wijgerde et al., 2005).

A comprehension of the signaling pathways involved in ovarian development will help design better strategies for the generation of higher quality IVM oocytes. This article discusses the sonic hedgehog (SHH) signaling pathway, which has been reported to be involved in folliculogenesis and oocyte maturation. We have further placed a special emphasis on the application of SHH-induced IVM systems owing to the widespread use of IVM oocytes both in research and in the production of genetically engineered animals via assisted reproductive technologies.

\section{Hedgehog signaling pathway in the ovaries}

HH signaling was first discovered in Drosophila (NüssleinVolhard and Wieschaus, 1980) and functions by controlling gonadal and basic embryonic developmental processes via regulating cell proliferation, differentiation, and cell fate determination through morphogen gradients (Ingham and McMahon, 2001). Till date, mammals are known to possess three HH ligands, namely Indian (IHH), Sonic (SHH), and Desert (DHH) (Hooper and Scott, 2005), all of which are capable of binding to patched (PTCH), a transmembrane receptor. In the absence of $\mathrm{HH}$ ligands, $\mathrm{PTCH}$ blocks the activity of smoothened (SMO), a transmembrane signal transducer protein. Binding of $\mathrm{HH}$ ligands to PTCH relieves SMO inhibition, and further downstream signal transduction occurs through the activation of the transcription factor, glioma-associated oncogene homolog (GLI) (Hooper and Scott, 2005). The consequent transcription of target genes including PTCH1 and GLI1 in response to $\mathrm{HH}$ signaling regulates cell proliferation, migration, and differentiation during development (McMahon et al., 2003).

All components of the HH signaling pathway including the ligands $(\mathrm{IHH}, \mathrm{SHH}$, and $\mathrm{DHH})$, the receptors (PTCH1 
and PTCH2), the signal transducer (SMO), and downstream transcription factor (GLI1) are expressed in the mammalian ovary (Russell et al., 2007). In addition, treatment of granulosa cells with SHH protein enhances granulosa cell growth and proliferation with concomitantly elevated expression of GLI1, a transcription target of $\mathrm{HH}$ signaling, thereby indicating that granulosa cells may be potential targets of HH signaling (Russell et al., 2007). Recent studies have identified components of the HH signaling pathway including PTCH, SMO, and GLI1 in the granulosa layers of the ovary in various species, such as mice (Wijgerde et al., 2005), cattle (Spicer et al., 2009), and pigs (Nguyen et al., 2009). Since communication between oocytes and surrounding somatic cells such as granulosa cells and theca cells is essential for follicle development (Wijgerde et al., 2005), it may be hypothesized that $\mathrm{HH}$ signaling could be involved in folliculogenesis and oocyte maturation.

\section{Sonic hedgehog signaling pathway and in vitro oocyte maturation}

The SHH signaling pathway is a complex signal transduction mechanism that controls precisely regulated developmental processes (Choudhry et al., 2014). Signal transduction via this pathway is initiated by the binding of SHH protein in an autocrine and/or paracrine fashion (Handrigan and Richman, 2010) and ultimately coordinates cell proliferation and differentiation in various cell types (Enomoto-Iwamoto et al., 2000; Osawa et al., 2006; Saldaña et al., 2016). However, the evidence that the SHH signaling pathway controls the development of ovarian follicles is of particular interest (Russell et al., 2007), since folliculogenesis and oocyte maturation proceed together until ovulation (Kidder and Vanderhyden, 2010). Several studies have demonstrated an association between $\mathrm{SHH}$ signaling pathway and oocyte maturation in vitro (Table 1). Treatment with recombinant SHH protein during IVM of pig oocytes was shown to promote nuclear maturation as well as pre-implantation embryonic development, which was reversed by the concomitant addition of cyclopamine, an SHH signaling inhibitor (Nguyen et al., 2009). Additionally, similar results on oocyte nuclear maturation were reported by Wang et al. by employing recombinant $\mathrm{SHH}$ protein and cyclopamine in caprine IVM medium (Wang et al., 2017). They further demonstrated that goat oocytes matured in the SHH protein supplemented medium demonstrated superior embryonic development both in vitro and in vivo (Wang et al., 2017). The results of these studies therefore directly imply that the SHH signaling pathway plays a key role in oocyte maturation.

The SHH signaling pathway can also be exploited as an indicator of oocyte quality. Previous reports have demonstrated that high-quality oocytes as assessed by brilliant cresyl blue (BCB) staining had greater potential to expand their surrounding cumulus cells along with reduced apoptosis and active SHH signaling (Lee et al., 2020). Highquality cumulus-oocyte complexes (COCs) in turn showed enhanced cumulus expansion, oocyte nuclear maturation, and preimplantation embryonic development. In addi-

Table 1. The role of sonic hedgehog (SHH) signaling pathway in in vitro maturation (IVM) of oocytes

\begin{tabular}{|c|c|c|c|c|}
\hline Supplement & Species & Effects & $\begin{array}{l}\text { Preimplantation embryonic } \\
\text { development }\end{array}$ & References \\
\hline Recombinant SHH protein & Pig & $\begin{array}{l}\text { Increased oocyte nuclear maturation, cyclin B1 } \\
\text { content, ERK1/2 phosphorylation, and intracellular } \\
\text { calcium release }\end{array}$ & $\begin{array}{l}\text { Enhanced cleavage, blastocyst } \\
\text { formation rates, and total cell } \\
\text { number after PA }\end{array}$ & (Nguyen et al., 2009) \\
\hline Recombinant SHH protein & Goat & $\begin{array}{l}\text { Increased oocyte nuclear maturation and ERK1/2 } \\
\text { phosphorylation }\end{array}$ & $\begin{array}{l}\text { Enhanced blastocyst formation } \\
\text { rate and in vivo development } \\
\text { after IVF }\end{array}$ & (Wang et al., 2017) \\
\hline Resveratrol & Pig & $\begin{array}{l}\text { Increased cumulus cell expansion, oocyte nuclear } \\
\text { maturation, and the expression of SHH-related } \\
\text { proteins (PTCH1, SMO, and GLI1) in both the } \\
\text { oocyte and its surrounding cumulus cells }\end{array}$ & $\begin{array}{l}\text { Enhanced cleavage, blastocyst } \\
\text { formation rates, and total cell } \\
\text { number after PA }\end{array}$ & (Lee et al., 2018) \\
\hline Melatonin & Pig & $\begin{array}{l}\text { Increased cumulus cell expansion and the expression } \\
\text { of } \mathrm{SHH} \text {-related proteins (PTCH1, SMO, and GLI1) in } \\
\text { both the oocyte and its surrounding cumulus cells }\end{array}$ & $\begin{array}{l}\text { Enhanced blastocyst formation } \\
\text { rate and total cell number } \\
\text { after PA }\end{array}$ & (Lee et al., 2017) \\
\hline
\end{tabular}

ERK1/2, extracellular signal-regulated protein kinase 1/2; PTCH1, patched 1; SMO, smoothened; GLI1, glioma-associated oncogene homolog 1; PA, parthenogenetic activation; IVF, in vitro fertilization. 


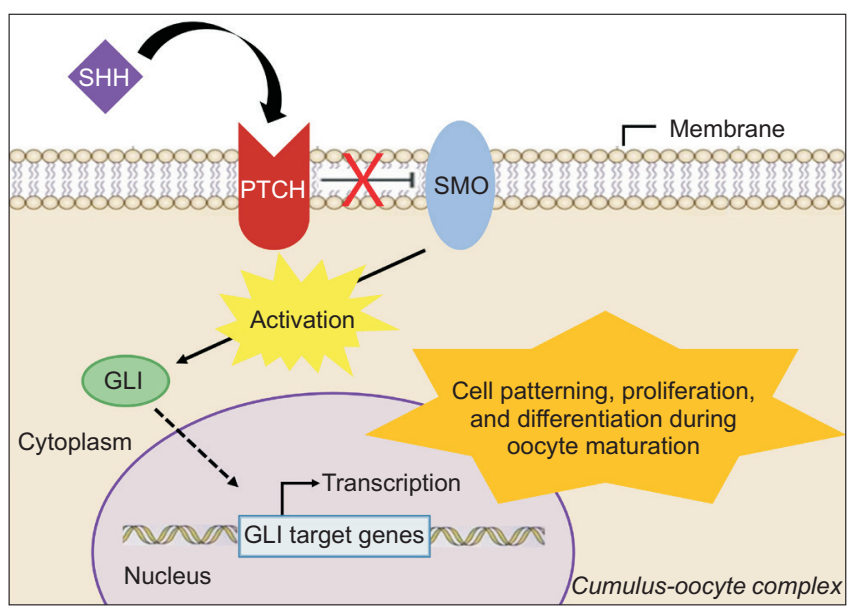

Fig. 1. Schematic illustration of the sonic hedgehog signaling pathway involved in oocyte maturation.

tion, they exhibited elevated expression of SHH signaling proteins including SHH, PTCH1, and GLI1 (Lee et al., 2020). The above findings collectively suggest that active signaling via the SHH pathway may be indispensible for the generation and/or maintenance of appropriate oocyte maturation environment.

Well-known antioxidants, such as resveratrol and melatonin, are known to activate the SHH signaling pathway in COCs and consequently improve oocyte maturation and subsequent embryonic development (Table 1). Lee et al. reported that the effect of resveratrol on cumulus cell expansion, oocyte nuclear maturation, and subsequent embryonic development in pigs is mediated via the SHH signaling pathway (Lee et al., 2018). Furthermore, improvement of cumulus cell expansion and subsequent embryonic development by melatonin has also been reported to occur through activation of SHH signaling (Lee et al., 2017). Given the relationship between SHH signaling pathway and oocyte maturation, it may be a suitable target for improving current IVM culture systems.

\section{CONCLUSION}

Recent studies have demonstrated the involvement of the SHH signaling pathway, which exists in ovarian follicles, in oocyte maturation (Fig. 1). In addition, it was also demonstrated that high quality oocytes have a greater potential to expand their surrounding somatic cells with active SHH signaling. Additionally, antioxidants including resveratrol and melatonin, improve oocyte maturation through $\mathrm{SHH}$ signaling activation. Therefore, activation of the SHH signaling pathway may aid in the establishment of an optimized IVM culture system by closely mimicking the in vivo environment of ovarian follicles.

Author Contributions: Conceptualization, S.L. and J.C.; investigation: S.L. and J.C.; writing - original draft preparation, S.L. and J.C.; writing - review \& editing: S.L. and J.C.

Funding: Not applicable.

Ethical Approval: Not applicable.

Consent to Participate: Not applicable.

Consent to Publish: Not applicable.

Availability of Data and Materials: Not applicable.

Acknowledgements: None.

Conflicts of Interest: No potential conflict of interest relevant to this article was reported.

\section{REFERENCES}

Abd El-Aziz AH, Mahrous UE, Kamel SZ, Sabek AA. 2016. Factors influencing in vitro production of bovine embryos: a review. Asian J. Anim. Vet. Adv. 11:737-756.

Appeltant R, Somfai T, Maes D, VAN Soom A, Kikuchi K. 2016. Porcine oocyte maturation in vitro: role of cAMP and oocyte-secreted factors - a practical approach. J. Reprod. Dev. 62:439-449.

Boyer A, Lapointe E, Zheng X, Cowan RG, Li H, Quirk SM, DeMayo FJ, Richards JS, Boerboom D. 2010. WNT4 is required for normal ovarian follicle development and female fertility. FASEB J. 24:3010-3025.

Choudhry Z, Rikani AA, Choudhry AM, Tariq S, Zakaria F, Asghar MW, Sarfraz MK, Haider K, Shafiq AA, Mobassarah NJ. 2014. Sonic hedgehog signalling pathway: a complex network. Ann. Neurosci. 21:28-31.

Das D and Arur S. 2017. Conserved insulin signaling in the regulation of oocyte growth, development, and maturation. Mol. Reprod. Dev. 84:444-459.

Enomoto-Iwamoto M, Nakamura T, Aikawa T, Higuchi Y, Yuasa T, Yamaguchi A, Nohno T, Noji S, Matsuya T, Kurisu K, Koyama E, Pacifici M, Iwamoto M. 2000. Hedgehog proteins stimulate chondrogenic cell differentiation and cartilage 
formation. J. Bone Miner. Res. 15:1659-1668.

Ferreira EM, Vireque AA, Adona PR, Meirelles FV, Ferriani RA, Navarro PA. 2009. Cytoplasmic maturation of bovine oocytes: structural and biochemical modifications and acquisition of developmental competence. Theriogenology 71: 836-848.

Gougeon A. 1996. Regulation of ovarian follicular development in primates: facts and hypotheses. Endocr. Rev. 17:121-155.

Grøndahl C. 2008. Oocyte maturation. Basic and clinical aspects of in vitro maturation (IVM) with special emphasis of the role of FF-MAS. Dan. Med. Bull. 55:1-16.

Handrigan GR and Richman JM. 2010. Autocrine and paracrine Shh signaling are necessary for tooth morphogenesis, but not tooth replacement in snakes and lizards (Squamata). Dev. Biol. 337:171-186.

Hatırnaz Ş, Ata B, Hatırnaz ES, Dahan MH, Tannus S, Tan J, Tan SL. 2018. Oocyte in vitro maturation: a sytematic review. Turk. J. Obstet. Gynecol. 15:112-125.

Hooper JE and Scott MP. 2005. Communicating with Hedgehogs. Nat. Rev. Mol. Cell Biol. 6:306-317.

Ingham PW and McMahon AP. 2001. Hedgehog signaling in animal development: paradigms and principles. Genes Dev. 15:3059-3087.

Jeon YE, Hwangbo Y, Kim SY, Park CK. 2020. Alpha-linolenic acid enhances maturation and developmental competence via regulation of glutathione, cAMP and fatty acid accumulation during in vitro maturation of porcine oocytes. J. Anim. Reprod. Biotechnol. 35:357-365.

Jin JX, Lee S, Khoirinaya C, Oh A, Kim GA, Lee BC. 2016. Supplementation with spermine during in vitro maturation of porcine oocytes improves early embryonic development after parthenogenetic activation and somatic cell nuclear transfer. J. Anim. Sci. 94:963-970.

Jing J, Jiang X, Chen J, Yao X, Zhao M, Li P, Pan Y, Ren Y, Liu W, Lyu L. 2017. Notch signaling pathway promotes the development of ovine ovarian follicular granulosa cells. Anim. Reprod. Sci. 181:69-78.

Kidder GM and Vanderhyden BC. 2010. Bidirectional communication between oocytes and follicle cells: ensuring oocyte developmental competence. Can. J. Physiol. Pharmacol. 88: 399-413.

Krisher RL. 2004. The effect of oocyte quality on development. J. Anim. Sci. 82 E-Suppl:E14-E23.

Lee S, Jin JX, Khoirinaya C, Kim GA, Lee BC. 2016. Lanosterol influences cytoplasmic maturation of pig oocytes in vitro and improves preimplantation development of cloned embryos. Theriogenology 85:575-584.

Lee S, Jin JX, Taweechaipaisankul A, Kim GA, Ahn C, Lee BC. 2017. Melatonin influences the sonic hedgehog signaling pathway in porcine cumulus oocyte complexes. J. Pineal Res. 63:e12424.

Lee S, Jin JX, Taweechaipaisankul A, Kim GA, Ahn C, Lee BC. 2018. Sonic hedgehog signaling mediates resveratrol to improve maturation of pig oocytes in vitro and subsequent preimplantation embryo development. J. Cell. Physiol. 233:
5023-5033.

Lee S, Kang HG, Jeong PS, Nanjidsuren T, Song BS, Jin YB, Lee SR, Kim SU, Sim BW. 2020. Effect of oocyte quality assessed by brilliant cresyl blue (BCB) staining on cumulus cell expansion and sonic hedgehog signaling in porcine during in vitro maturation. Int. J. Mol. Sci. 21:4423.

Lee S, Park EJ, Moon JH, Kim SJ, Song K, Lee BC. 2015. Sequential treatment with resveratrol-trolox improves development of porcine embryos derived from parthenogenetic activation and somatic cell nuclear transfer. Theriogenology 84:145154.

Li L, Shi X, Shi Y, Wang Z. 2021. The signaling pathways involved in ovarian follicle development. Front. Physiol. 12: 730196.

Lonergan P and Fair T. 2016. Maturation of oocytes in vitro. Annu. Rev. Anim. Biosci. 4:255-268.

Luciano AM and Sirard MA. 2018. Successful in vitro maturation of oocytes: a matter of follicular differentiation. Biol. Reprod. 98:162-169.

Marchal R, Caillaud M, Martoriati A, Gérard N, Mermillod P, Goudet G. 2003. Effect of growth hormone (GH) on in vitro nuclear and cytoplasmic oocyte maturation, cumulus expansion, hyaluronan synthases, and connexins 32 and 43 expression, and GH receptor messenger RNA expression in equine and porcine species. Biol. Reprod. 69:1013-1022.

Marín Bivens CL, Grøndahl C, Murray A, Blume T, Su YQ, Eppig JJ. 2004. Meiosis-activating sterol promotes the metaphase I to metaphase II transition and preimplantation developmental competence of mouse oocytes maturing in vitro. Biol. Reprod. 70:1458-1464.

McMahon AP, Ingham PW, Tabin CJ. 2003. Developmental roles and clinical significance of hedgehog signaling. Curr. Top. Dev. Biol. 53:1-114.

Moawad AR, Ghoneim IM, Darwish GM, Badr MR, El-Badry DA, EL-Wishy ABA. 2020. Factors affecting in vitro embryo production: insights into dromedary camel. J. Anim. Reprod. Biotechnol. 35:119-141.

Nguyen NT, Lin DP, Yen SY, Tseng JK, Chuang JF, Chen BY, Lin TA, Chang HH, Ju JC. 2009. Sonic hedgehog promotes porcine oocyte maturation and early embryo development. Reprod. Fertil. Dev. 21:805-815.

Nilsson E and Skinner MK. 2001. Cellular interactions that control primordial follicle development and folliculogenesis. J. Soc. Gynecol. Investig. 8(1 Suppl Proceedings):S17-S20.

Nüsslein-Volhard C and Wieschaus E. 1980. Mutations affecting segment number and polarity in Drosophila. Nature 287: 795-801.

Osawa H, Ohnishi H, Takano K, Noguti T, Mashima H, Hoshino H, Kita H, Sato K, Matsui H, Sugano K. 2006. Sonic hedgehog stimulates the proliferation of rat gastric mucosal cells through ERK activation by elevating intracellular calcium concentration. Biochem. Biophys. Res. Commun. 344:680687.

Palma GA, Argañaraz ME, Barrera AD, Rodler D, Mutto AÁ, Sinowatz F. 2012. Biology and biotechnology of follicle de- 
velopment. ScientificWorldJournal 2012:938138.

Paulini F, Silva RC, Rôlo JL, Lucci CM. 2014. Ultrastructural changes in oocytes during folliculogenesis in domestic mammals. J. Ovarian Res. 7:102.

Russell MC, Cowan RG, Harman RM, Walker AL, Quirk SM. 2007. The hedgehog signaling pathway in the mouse ovary. Biol. Reprod. 77:226-236.

Saadeldin IM and Cho J. 2021. Current approaches for assisted oocyte maturation in camels. J. Anim. Reprod. Biotechnol. 36:162-167.

Saldaña JI, Solanki A, Lau CI, Sahni H, Ross S, Furmanski AL, Ono M, Holländer G, Crompton T. 2016. Sonic Hedgehog regulates thymic epithelial cell differentiation. J. Autoimmun. 68:86-97.

Spicer LJ, Sudo S, Aad PY, Wang LS, Chun SY, Ben-Shlomo I, Klein C, Hsueh AJ. 2009. The hedgehog-patched signaling pathway and function in the mammalian ovary: a novel role for hedgehog proteins in stimulating proliferation and ste- roidogenesis of theca cells. Reproduction 138:329-339.

Sugimura S, Yamanouchi T, Palmerini MG, Hashiyada Y, Imai K, Gilchrist RB. 2018. Effect of pre-in vitro maturation with cAMP modulators on the acquisition of oocyte developmental competence in cattle. J. Reprod. Dev. 64:233-241.

Wang DC, Huang JC, Lo NW, Chen LR, Mermillod P, Ma WL, Chiang HI, Ju JC. 2017. Sonic Hedgehog promotes in vitro oocyte maturation and term development of embryos in Taiwan native goats. Theriogenology 103:52-58.

Wang HX, Li TY, Kidder GM. 2010. WNT2 regulates DNA synthesis in mouse granulosa cells through beta-catenin. Biol. Reprod. 82:865-875.

Wijgerde M, Ooms M, Hoogerbrugge JW, Grootegoed JA. 2005. Hedgehog signaling in mouse ovary: Indian hedgehog and desert hedgehog from granulosa cells induce target gene expression in developing theca cells. Endocrinology 146:35583566. 